\title{
JuAn Recio Aragonés, un JUDEOCONVERSO ENTRE LA ÉLITE LUCENTINA ${ }^{1}$
}

\author{
Francisco Indalecio Quevedo Sánchez \\ Universidad de Granada
}

\begin{abstract}
Resumen
En los últimos años se está superando la tradicional forma de estudiar al mundo judeoconverso, en la que la relación de la minoría con la Inquisición era el objeto principal de estudio, dejándose de lado la investigación de los confesos en sí mismos y de su integración social. Hoy sabemos que los cristianos nuevos no sólo sobrevivieron a persecuciones populares e institucionales, sino que lograron su total asimilación en todos los estratos de la sociedad. Ejemplos como el de la familia Aragonés muestran que muchos pasaron de la supervivencia al ennoblecimiento, no sin esfuerzo, no sin poner en marcha una serie de estrategias encaminadas, principalmente, a lograr la ocultación de su progenie y el enriquecimiento.
\end{abstract}

\section{Palabras Clave}

Genealogía; ascenso social; ocultación; judeoconversos; enriquecimiento.

\begin{abstract}
In recent years, the traditional way of studying the world of Jewish converts, in which the relations between minority and Inquisition was the main subject of study, is being overcome, leaving aside the research on the confesos themselves. Nowadays we know that new Christians not only survived public and institutional persecutions but also managed to achieve their total assimilation among all social strata. Examples such as that of the Aragonés lineage demonstrates that many of them went from survival to nobility. Although this was not achieved without effort and neither without setting a series of strategies, mainly aimed to getting enriched and hiding their ascendence.
\end{abstract}

\section{Keywords}

Genealogy; Upward mobility; concealment; Jewish converts; enrichment.

\section{Resumo}

Nos últimos anos, temos superado uma forma tradicional de estudar o mundo cristão-novo, no qual a relação desta minoria com a Inquisição era o principal objeto de estudo. Ficava algo esquecida, assim, a investigação dos próprios cristãos-novos per se a sua integração social. Hoje sabemos que os cristãosnovos não apenas sobreviveram à perseguição popular e institucional, mas também conseguiram a assimilação social em diversos grupos. Exemplos como o da família Aragonés mostram que muitos passaram da sobrevivência ao enobrecimento, não sem esforço, não sem pôr em marcha uma série de estratégias destinadas, principalmente, a conseguir a ocultação da ascendência e o enriquecimento.

\section{Palavras chave}

Genealogia; ascenso social; ocultação; cristãos-novos; enriquecimento.

\footnotetext{
1 "Este trabajo se inscribe en el marco del Proyecto de Investigación "Nobles judeoconversos (II). La proyección patrimonial de las élites judeoconversas andaluzas (ss. XV-XVII)"(HAR2015-68577) financiado por el Ministerio de Economía y Competitividad". Correo electrónico: curro.quevedo.sanchez@gmail.com.
} 


\section{Introducción}

La tradicional visión sobre el mundo judeoconverso comienza a superarse con las publicaciones y trabajos realizados en los últimos años ${ }^{2}$, que en general siguen la estela de los ya clásicos de Domínguez Ortiz, Caro Baroja o Márquez Villanueva³ ${ }^{3}$ No obstante, hasta hace relativamente poco, salvo honrosas excepciones, hablar de judeoconversos era hablar de judaizantes. La investigación sobre la minoría hebrea por lo general trabajó la documentación inquisitorial ${ }^{4}$ y profundizó, por tanto, en la relación del grupo con el Santo Oficio. Este sesgo herético de los estudios históricos ha sepultado una realidad en nuestra opinión mucho más importante.

2 Entre otros muchos, resultan de enorme interés: Jaime Contreras ConTreras, Sotos contra Riquelmes: regidores, inquisidores, criptojudios, ed. Anaya, Madrid, 1992; Pilar Huerga Criado, En la Raya de Portugal: solidaridad y tensiones en la comunidad judeoconversa, ed. Universidad de Salamanca, Salamanca, 1994; Francisco José Aranda Pérez, Poder Municipal y cabildo de jurados en Toledo en la Edad Moderna, ed. Ayuntamiento de Toledo, Toledo, 1992 y "Judeoconversos y poder municipal en Toledo en la Edad Moderna: una discriminación poco efectiva", Actas de la IV Reunión Científica de la Asociación Española de Historia Moderna, Antonio Maestre Sanchís, Pablo Fernández Albaladejo y Enrique Giménez López (coords.), ed. Universidad de Alicante, Alicante, 1997, pp. 155-168; Julio VAldeón Baruque, Judios y conversos en la Castilla medieval, ed. Ámbito, Valladolid, 2000; Juan Ignacio Pulido Serrano, Los conversos en España y Portugal, ed. Arco, Madrid, 2003; Enrique Soria MESA, "Los judeoconversos granadinos en el siglo XVI: Nuevas fuentes, nuevas miradas", Estudios sobre Iglesia y Sociedad en Andalucía en la Edad Moderna, Antonio Luis Cortés Peña y Miguel Luis López-Guadalupe (eds.), ed. Universidad de Granada, Granada, 1999, pp. 101-109 y "Burocracia y conversos. La Real Chancillería de Granada en los siglos XVI y XVII", Letrados, juristas y burócratas en la España Moderna, Francisco José Aranda Pérez (coord.), ed. Universidad de Castilla la Mancha, Cuenca, 2005, pp.107-144.

3 Antonio Domínguez Ortiz, Los judeoconversos en España y América, ed. Istmo, Madrid, 1978; La clase social de los conversos en Castilla en la Edad Moderna, ed. Universidad de Granada, 1991 y Los judeoconversos en la España Moderna, ed. Mapfre, Madrid, 1992; Julio Caro Baroja, Los judios en la España Moderna y Contemporánea, ed. Istmo, Madrid, 2000, $4^{a}$ ed., 2 vols.; Francisco Márquez Villanueva, De la España judeoconversa. Doce estudios, ed. Bellaterra, Barcelona, 2006.

4 entre otros: Jaime Contreras Contreras y J.P. Dedieu, "Geografía de la Inquisición española. La formación de los distritos (1470-1820)”, Hispania, 40-144 (1980), pp. 37-93.; Joaquín Pérez VillanueVA, Bartolomé Escandell Bonet y Ángel Alcalá Galve (dirs.), Historia de la Inquisición en España y América, ed. Biblioteca de Autores Cristianos, Madrid, 1984-2000, 3 vols..; Ricardo García CÁrCel y Doris Moreno, Inquisición: Historia Crítica, ed. Temas de Hoy, Madrid, 2000; Joseph Pérez, La inquisición española: crónica negra del Santo Oficio, ed. Martínez Roca, Barcelona, 2005; José Martínez Millán, La Inquisición española, ed. Alianza, Madrid, 2007; Henry Kamen, La Inquisición española: una revisión crítica, ed. Crítica, Barcelona, 2011. Particularmente nos interesan los trabajos que estudian la Inquisición cordobesa y granadina, escasos, pero valiosos para el que escribe. En primer lugar destacaría las recopilaciones documentales de Rafael Gracia Borx, Colección de documentos para la historia de la Inquisición de Córdoba, ed. Monte de Piedad y Caja de Ahorros de Córdoba, Córdoba, 1982 y, sobre todo, Autos de Fe y causas de la Inquisición de Córdoba, ed. Diputación de Córdoba, Córdoba 1983 y José Antonio Martínez BARA, Catálogo de informaciones genealógicas de la Inquisición de Córdoba conservadas en el Archivo Histórico Nacional, ed. Dirección General de Archivos y Bibliotecas, Madrid, 1970, 2 vols., Pero de entre todos resulta de enorme interés el artículo de Ana Cristina CuAdro GarCía, "Acción inquisitorial contra los judaizantes en Córdoba y crisis eclesiástica (1482-1508)", Revista de Historia Moderna. Anales de la Universidad de Alicante, 21 (2003), pp. 11-28 y el libro de Andrés Acosta GonzÁlez, Estudio comparado de tribunales inquisitoriales (periodos 1540-1570 y 1571-1621), ed. UNED, Madrid, 1990. 
La historia de los judeoconversos no acabó con las persecuciones populares, con los masivos autos de fe, con las migraciones forzosas, ni siquiera con la reinserción de muchos de los reconciliados y condenados mediante las composiciones, acontecimientos producidos en los siglos finales del Medievo. Superados los "años duros" todo aquél que lograra la supervivencia física tendría que tratar de integrarse en un mundo hostil, pues el odio al judío medieval, que desembocó en las terribles matanzas de 1391, fue una cruel herencia recibida por el converso, que vio deteriorada su imagen a lo largo del siglo XV, hasta imponerse una animadversión generalizada que permaneció durante toda la Época Moderna.

Sin embargo, hoy sabemos que a pesar de todos los obstáculos no sólo lograron la integración, sino que jugaron un papel esencial en aquella España, por lo que podríamos decir que los conversos fueron una minoría, sí, pero marginada tan sólo en coyunturas y circunstancias concretas.

Tras los años más duros, sin duda enmarcados entre 1449 -sucesos de Toledo- y 1520 -momento en el que la persecución inquisitorial comenzó a mitigarse-, los conversos lograron poco a poco su completa asimilación en la sociedad cristianovieja, no sin dificultades, no sin poner en marcha una serie de estrategias encaminadas fundamentalmente a ocultar su ascendencia, motivo suficiente para sufrir el desprecio social e institucional -limpieza de sangre-. Tras estos años algunos lograron la supervivencia y llevar a cabo una vida relativamente tranquila; otros muchos, los más ambiciosos, aprovecharon los resortes del sistema para conseguir la ocultación, primero, el enriquecimiento, después, y finalmente la promoción social. El camino para lograrlo, sin embargo, no fue sencillo.

De aquí surge la necesidad de realizar estudios como el que aquí presentamos, que hunden sus raíces en la Baja Edad Media, pero que tratan de analizar el devenir de los linajes y del grupo más allá de los estrictos marcos temporales impuestos por la historiografía. No podemos obviar la continuidad histórica -entre lo medieval y lo moderno- de algunos fenómenos sociales. Por ello nuestro trabajo no comienza y termina en la Edad Media, sino que penetra profundamente en la Edad Moderna, pues no se podría entender la historia de estas familias sin conocer su evolución a lo largo del tiempo, especialmente dos siglos, el XV y el XVI, en los que el converso fue el principal protagonista. Veámoslo.

\section{Orígenes familiares}

Nos encontramos aquí ante uno de los ejemplos más interesantes de un proceso de ascenso social y ocultación llevado a cabo por un linaje converso cordobés ${ }^{5}$. Si empe-

\footnotetext{
5 Los conversos cordobeses no han sido estudiados en profundidad, pero contamos con valiosos trabajos, entre los que destacan, por ejemplo, los de Emilio Cabrera MuÑoz, "Los conversos de Baena en el Siglo XV", Meridies, 5-6 (2002), pp. 243-267; Miguel Ángel Ladero Quesada, "Los conversos de Córdoba en 1497", El Olivo, 29-30 (1989), pp. 187-205; Margarita CABrera SÁnchez, "El problema converso en Córdoba. El incidente de la Cruz del Rastro", La Península Ibérica en la era de los Descubrimientos: 1391-1492: III Jornadas Hispano-Portuguesas de Historia Medieval, Manuel González Jiménez (ed.) e Isabel Montes
} 
záramos la historia por el final pensaríamos que nada tenía que esconder una estirpe que contaba en el siglo XVII con familiares y comisarios del Santo Oficio, Caballeros de Calatrava y Alcántara, Alguaciles Mayores, Regidores, Hidalgos, señores de Vasallos y, finalmente, marqueses. Una familia eminentemente noble tras un proceso de ascenso social desarrollado durante siglos y que nos lleva desde aljabibes y plateros reconciliados por la Inquisición a finales del siglo XV hasta marqueses a comienzos del XIX. En medio, todo un proceso de ocultación y de ascenso social rompió otra vez más lo legalmente establecido y demostró no sólo la existencia de movilidad social, sino que en ella se vieron implicados cientos e incluso miles de conversos ${ }^{6}$.

El apellido Aragonés es común y especialmente recurrente en diversos linajes conversos, muchos de ellos emparentados, aunque sea en grado remoto, y posiblemente provenientes de un tronco común. En un reciente trabajo, Barea López afirma que es un apellido oriundo de Aragón y una rama afincada en Córdoba, reconciliada por la Inquisición, se dispersa en el Quinientos por diversos pueblos del reino como Fernán Núñez, Lucena, Priego o Palma del Río?

Romero-Camacho y Antonio María Claret (coords.), ed. Junta de Andalucía, Sevilla, 1997, vol. 1, pp. 331 339. La obra de Enrique Soria MesA, El cambio inmóvil: transformaciones y permanencias en una élite de poder (Córdoba, ss. XVI-XIX), ed. Posada, Córdoba 2000 muestra ejemplos de importantes linajes conversos cordobeses entre sus páginas; Rocío Velasco TEJedor, «De financieros judeoconversos a nobleza titulada. Las estrategias de ascenso social de la familia Pisa (siglos XVI-XVII)», Historia y Genealogía, 3 (2013), pp. 243-2617. Destacar, también, el reciente trabajo sobre el linaje Herrera del profesor Enrique SoRIA MESA, "De la represión Inquisitorial al éxito social. La capacidad de recuperación de los judeoconversos andaluces entre los siglos XV-XVII: el ejemplo del linaje Herrera", Medievalismo, 24 (2014), pp. 399-417. Junto a Otero Mondejar ha publicado recientemente un interesante trabajo denominado "Los judeoconversos de Baena (siglos XV-XVII). Rechazo e integración social", ITVCI. Revista de difusión cultural de Baena y su Comarca, 4 (2014), pp. 95-106. en el que realizan un primer acercamiento al estudio de relevantes linajes conversos de Baena (Córdoba), como los Contador, Monte de Mendoza, los Racimo o los Yáñez Dávila. Sobre linajes poco conocidos, pero que llevaron a cabo un importante ascenso social han girado algunos de mis propios trabajos: "Un linaje en expansión. De penitenciados por el Santo Oficio a élite social: La familia Sánchez de Ávila", Familia y economía en los territorios de la Monarquía Hispánica (ss. XVI-XIX), Raúl Molina Recio (dir.), ed. Mandalay, Badajoz, 2014, pp. 201-238; "Francisco de Torreblanca y Villalpando: jurista, religioso, escritor, patrono.... Converso", II Encuentro de Jóvenes Investigadores en Historia Moderna, Félix Labrador Arroyo (ed.), Madrid, 2013, pp. 273-291.; "Inventando el pasado. La familia judeoconversa Herrera de Córdoba y Granada", ANAHGRAMAS, 1 (2014), pp. 235-272.; "Estrategias familiares con fines económicos y sociales. El caso del jurado Martín Gómez de Aragón", Revista de Historia y Genealogía, 3 (2013), pp. 65-82.; "Nobles judeoconversos: los oscuros orígenes del linaje Córdoba-Ronquillo", Sefarad, 76-2 (2016), pp. 363-396.

6 Hace años, uno de mis primeros trabajos versó sobre esta familia: "La limpieza de sangre como conflicto en la España Moderna. Los Recio Aragonés de Lucena, de judíos a marqueses", Actas de la XI Reunión Científica de la Fundación Española de Historia Moderna, Juan Luis Castellano Castellano y Miguel Luís López-Guadalupe Muñoz, ed. Universidad de Granada, Granada, 2012, Vol. 2, pp. 557-570.

7 Oscar Barea López, Heráldica y genealogía de los linajes de Cabra de Córdoba, Doña Mencía y Monturque y de sus enlaces (Ss. XV-XIX), ed. Bubok Publishing S.L, Madrid, 2013, p. 234. 
Años antes, Soria Mesa defendía el mismo origen geográfico de los Aragonés cordobeses. Señalaba en un artículo hoy todavía inédito, que el linaje Aragonés se convirtió ${ }^{8}$

"En una de las piezas claves del funcionamiento y evolución de la comunidad conversa de la ciudad (Córdoba) e incluso de la región andaluza. Seguramente oriundos de Aragón, de ahí el apellido, radicaron en la capital cuando menos desde mediados del siglo $\mathrm{XV}$, y se fueron diversificando en numerosas ramas, casi todas ellas relacionadas entre sí de formas diversas a medida que fueron transcurriendo las generaciones"

Aceptando su naturaleza aragonesa, sabemos que uno de sus primeros destinos fue la villa de Palma del Río, buscando precisamente la protección, en este caso, de la familia Portocarrero. Es de sobra conocido que las cortes señoriales fueron protectoras de unos servidores tan útiles como los conversos en el siglo XV y aquí posiblemente comenzaron a florecer los Aragonés ${ }^{9}$. Pronto se avecindarían por distintos lugares del reino, incluida la capital, bajo la protección del Señor de Aguilar, donde varios de ellos desfilaron ante el Santo Oficio para habilitarse ${ }^{10}$. Multitud de ramas de este linaje se extenderían, por tanto, por pueblos del reino de Córdoba e incluso por el vecino reino de Granada, generando una compleja red de parentesco ${ }^{11}$.

Sea como fuere, Aragonés es uno de esos apellidos que en Córdoba despierta inmediatamente suspicacias, aunque no siempre es fácil relacionarlo con un antepasado penitenciado o con personajes indiscutiblemente hebreos. Sin embargo, creemos que sobran indicios para pensar que todo aquél que portaba dicho apellido podía tener progenie

\footnotetext{
8 Enrique Soria Mesa, "Las élites judeoconversas en la Andalucía de los siglos XVI y XVII", p. 4, en prensa. Agradezco al autor que me haya facilitado un ejemplar antes de su publicación.

9 Efectivamente, hallamos multitud de escrituras de vecinos de la Villa de Palma del Río que portaban el apellido Aragonés, dedicados en su mayoría al comercio en el siglo XVI.

10 Con la ayuda de Enrique Soria Mesa, codirector de mi tesis doctoral, he trabajado en profundidad la Composición o habilitación de los judeoconversos cordobeses producida en 1497. Un documento esencial contenido en el legajo 100 de la Contaduría Mayor de Cuentas (en adelante CMC) del Archivo General de Simancas (en adelante AGS). A espera de una próxima publicación, podemos decir que de dicha fuente documental hemos obtenido cifras realmente impresionantes para la ciudad de Córdoba, pues de sus 942 asientos obtuvimos el nombre, apellidos, oficio, ubicación en la ciudad, etc. de 1.716 judeoconversos cordobeses en una fecha clave, 1497. De ellos varios portan el apellido Aragonés: Asiento 44. Alonso Aragonés y Beatriz Jiménez, vecinos de Santa María, reconciliados, 1.200 maravedís; Asiento 143. Gonzalo Aragonés, corredor, e Mencía Fernández, su mujer, vecinos de Santa María, son reconciliados y ella hija de condenado, 1.200 maravedís; Asiento 192. Juan Aragonés, sedero, e Leonor Fernández, su mujer, vecinos de santa María, son reconciliados, 2.000 maravedís; Asiento 553. Fernando Aragonés, aljabibe, vecino de san Pedro, es reconciliado, 800 maravedís; Asiento 873. Fernando Aragonés, buhonero, e Isabel Jiménez, su mujer, vecinos de Ómnium Sanctórum, es reconciliado, 1.200 maravedís. (AGS, CMC, leg. 100, s.f.)

11 Enrique Soria Mesa, Las élites judeoconversas en la Andalucía de los siglos XVI y XVII..., pp. 6-7. El manejo de la documentación de los archivos locales cordobeses permite al profesor Soria hacer dicha afirmación.
} 
hebrea -precisamente cuando lograban un cierto estatus se deshacían inmediatamente de tan notado patronímico-. Analizaremos aquí una de sus ramas, la afincada en la populosa villa de Lucena, posiblemente la que mayor éxito social obtuvo, aunque una probanza en pleno fervor estatutario a punto estuvo de paralizar el vertiginoso ascenso de los Aragonés lucentinos.

Lo cierto es que de no ser por la limpieza de sangre nada o prácticamente nada sabríamos de algunas historias de éxito social que encerraban tras de sí todo un proceso de ocultación. En ocasiones los problemas ante las probanzas, las superaran o no, nos permiten conocer el origen del candidato y, por extensión, de todo su linaje ${ }^{12}$. Dando por hecho la existencia de una incesante movilidad social, la simple conversión habría abierto las puertas de la alta sociedad a los judeoconversos enriquecidos, pero la limpieza de sangre les obligó a demostrar documentalmente lo que no eran si pretendían el acceso a cualquier cargo u honor. Hoy sabemos que a la larga la limpieza de sangre fue un trámite, fácilmente superable con poder, influencias políticas y dinero, pero también fue el escenario principal de confrontación, y el converso estaba a expensas de que un memorial anónimo, un testigo malintencionado o un linajudo, sacara a relucir su progenie, como ocurrió en este caso ${ }^{13}$.

\footnotetext{
12 Para obtener una visión general sobre la cuestión de la limpieza de sangre, véase: Albert Sicroff, Los estatutos de limpieza de sangre: controversias entre los siglos XV y XVII, ed. Taurus, Madrid 1979; algunos de los trabajos citados de Domínguez Ortiz y Caro Baroja y, sobre todo, los recientes estudios de Juan Hernández Franco, Cultura y Limpieza de Sangre en la España Moderna. Puritate Sanguinis, ed. Universidad de Murcia, Murcia, 1996 y Sangre limpia, sangre española: el debate sobre los estatutos de limpieza (siglos XV-XVII), ed. Cátedra, Madrid, 2011).

13 Dichas cuestiones son analizadas en interesantes trabajos, como por ejemplo algunos del profesor SoRIA MesA: "Genealogía y poder. Invención del pasado y ascenso social en la España Moderna", Estudis, 30 (2004), pp. 21-55 o "Los Linajudos. Honor y conflicto social en la Granada del Siglo de Oro", Violencia y conflictividad en el universo barroco, Julián Lozano Navarro y Juan Luis Castellano (coords.), ed. Comares, Granada, 2010, pp. 401-427. Otros historiadores que han trabajado estas cuestiones son, por ejemplo, Jaime Contreras, "Linajes y cambio social: la manipulación de la memoria", Historia Social, 21 (1995), pp. 105-124. о María del Pilar RÁbade OBRAdó, "La invención como necesidad: genealogía y judeoconversos", Estudios de Genealogía, Heráldica y Nobiliaria, Editorial Complutense, Miguel Ángel Ladero Quesada (coord.), ed. Universidad Complutense de Madrid, Madrid, 2006, pp. 183-201. Hoy sabemos, gracias a estos escasos pero valiosos trabajos que en un contexto marcado por la limpieza de sangre, numerosos linajes se sirvieron de estas y otras estrategias para poder demostrar lo que no eran ni de lejos, limpios de sangre. Entre lo más recientemente publicado algunos de mis estudios han versado sobre esta cuestión, como "Engaño genealógico y ascenso social. Los judeoconversos cordobeses", De la tierra al cielo. Líneas recientes de Investigación en Historia Moderna. I Encuentro de Jóvenes Investigadores en Historia Moderna, Eliseo Serrano Martín (Coord.), ed. Diputación de Zaragoza, Zaragoza, 2013, pp. 809-829. También resulta de interés un reciente artículo de Baltasar CUART Moner, en el que demuestra la manipulación de la memoria llevada a cabo por los candidatos a ingresar en los prestigiosos Colegios Mayores salmantinos para superar las pruebas de limpieza en "El juego de la memoria. Manipulaciones, reconstrucciones y reinvenciones de linajes en los colegios mayores salmantinos durante el siglo XVI", Cultura, política y práctica del derecho, S. De Dios y E. Torijano Pérez, (coords.) ed. Universidad de Salamanca, Salamanca, 2012, pp. 71-141.
} 
Concretando en el tema, Juan Recio Aragonés ya era regidor de la Villa de Lucena cuando decidió presentar su candidatura para familiar del Santo Oficio, vacante por el fallecimiento de Pedro Fernández Rico en $1612^{14}$. Los trámites para su acceso comenzaron el 24 de octubre de ese año y siguiendo el proceso habitual el regidor declaró sus antepasados y los de su mujer, y los inquisidores iniciaron las diligencias para contrastar la información y despacharle título si no hallaban problema.

Dejemos de un lado momentáneamente la familia de la mujer, aparentemente limpia de sangre. Juan Recio decía ser hijo de Gonzalo Aragonés, natural de Córdoba, y Leonor Fernández "la Recia", natural de Lucena. Sus abuelos paternos eran Fernando Aragonés y Catalina González, vecinos de Córdoba y los maternos Juan Recio y María Fernández Casamentero y Rico, vecinos de Lucena.

Presentados unos cuantos testigos que refrendaban la nobleza de los "Aragonés de Lucena", supuestamente deudos de Alonso Aragonés, vecino de Fernán Núñez y escudero de don Diego de Sousa, de demostrada limpieza, los inquisidores aprobaron las informaciones en 1613 y acordaron llamar al pretendiente para que hiciera el juramento y se le despachara el título ${ }^{15}$.

Cuál sería la sorpresa de los inquisidores y del propio candidato cuando pocos días después de llegar a este acuerdo fue recibido en el tribunal, el 18 de enero de 1613, un memorial anónimo que desvelaba el auténtico origen social del creso regidor, su ascendencia maculada. Podríamos pensar que el documento era fruto de la maledicencia, de las envidias, de las rivalidades por la familiatura, pero sabemos que es cierto porque confirma lo que años antes habían declarado ante el Santo Oficio varios antepasados de Juan Recio Aragonés, como veremos.

El escrito anónimo era rotundo. Juan Recio Aragonés no era quien decía ser. No provenía de los Aragonés de Fernán Núñez, supuestamente limpios de sangre, sino de los Aragonés de Córdoba, confesos, descendientes de penitenciados por el Santo Oficio. Su abuelo paterno Fernando Aragonés, no era natural de Fernán Núñez, sino natural de Córdoba, descendiente de condenados por la Inquisición. Uno de sus hijos, el platero Gonzalo Aragonés, padre del pretendiente, habría marchado a Lucena en 1555 junto a dos hermanos llamados Ciscos y Pedro, también plateros. Todos eran naturales de Córdoba, todos eran confesos "que se dice públicamente entre la gente común que si se ponen cien cruces, no le tendrían por cristiano viejo", se afirmaba en dicho memorial $^{16}$. No sólo se revelaba su ascendencia manchada, sino que también se decía que su supuesta relación familiar con los de Fernán Núñez era un invento, y que el Comisario del Santo Oficio encargado de la investigación era su compadre y amigo.

\footnotetext{
14 Los datos sobre su proceso han sido obtenidos del Archivo Histórico Nacional (en adelante AHN), Inquisición, leg. 5213, exp. 7, recogido por José Antonio MARTínez BARA, Catálogo de informaciones genealógicas de la Inquisición de Córdoba conservadas en el Archivo Histórico Nacional, ed. Dirección General de Archivos y Bibliotecas, Madrid, 1970, p. 686.

15 José Antonio Martínez Bara, Catálogo de informaciones genealógicas..., p. 686.

16 Los datos son obtenidos del AHN, Inquisición, leg. 5213, exp. 7.
} 
Los Inquisidores se pusieron en marcha, aunque quizá no con el rigor que cabría esperar. Preguntaron a varios testigos en Córdoba, como el platero Luis Fernández, y todos confirmaron que eran confesos con mala opinión. Sin embargo, las pruebas no eran irrefutables, y los inquisidores no hallaron o no quisieron hallar las declaraciones de sus genealogías que los antepasados de Juan Recio, como conversos, hicieron en diversos periodos entre 1500 y $1567^{17}$. Tal sería el poder e influencia del regidor que ante tal ofensa, según él fruto de los odios y envidias locales, hizo recusación de testigos y presentó nuevos documentos, lo que le valió para que finalmente en 1614 fueran aprobadas las informaciones por el Consejo después de ser votadas en discordia en Córdoba.

Hoy, sin embargo, podemos conocer muchos más datos sobre su historia real y contrastarla con la que oficialmente alegó el Regidor para defenderse de las terribles acusaciones vertidas contra su honor y limpieza. Veámoslo.

\section{Un converso entre la élite lucentina}

El recurso del regidor fue simplemente hacerse descender de unos Aragonés de Fernán Núñez, que por otro lado desconocernos si eran o no realmente limpios de sangre, por más que contaran a fines del XVI con un comisario y un familiar del Santo Oficio. Para ello presentó la carta dotal de un supuesto hermano de su abuelo llamado Francisco Fernández Aragonés, vecino de Fernán Núñez, casado en 1500 con una tal Mayor Díaz de Cañete. Dos nietos de estos fueron Martín Fernández Aragonés, comisario del Santo Oficio (1590) y Pedro Heredia Fernández Aragonés, familiar del Santo Oficio (1592) y Alcalde de la Hermandad del Estado de Hidalgos (1613), supuestos deudos del regidor lucentino. Hoy sabemos que nada tenían que ver con él, y que se sirvió de coincidencias (tenían mismos nombres y apellidos) para demostrar una falsa ascendencia.

La historia comienza a esclarecerse poco después de que se le despachara título a Juan Recio y, con ello, quedara demostrada su pureza. No queremos descartar su posible relación familiar con la rama de Fernán Núñez, quizá también conversos, pero lo cierto es que gracias a informaciones posteriores, contenidas en el mismo expediente del Archivo Histórico Nacional, hoy conocemos con certeza su historia.

\footnotetext{
17 Estas genealogías fueron halladas en el Archivo Histórico Nacional por el profesor Enrique Soria Mesa, a quien agradezco enormemente que me cediera las referidas al reino de Córdoba, concretamente 121 contenidas originalmente en los libros $1^{\circ}, 2^{\circ}$, y $3^{\circ}$ de genealogías de Córdoba, el libro $1^{\circ}$ de genealogías nuevas de Córdoba y los libros de genealogías de Palma del Río, Baena, Castro del Río, Luque, Cabra, Bujalance, Adamuz, Puente don Gonzalo y Estepa. De aquí obtuvimos datos de cientos de personas pertenecientes al colectivo converso, principalmente el de la capital. Estas genealogías, junto al análisis de la antedicha composición de 1497 constituyeron la base de mi tesis doctoral.
} 
El 1 de julio de 1615 fueron halladas por el tribunal de Córdoba una serie de genealogías inquisitoriales con motivo de una carta del tribunal de Valencia en que se solicitaba que se hiciese información de la hija de Juan Recio Aragonés, llamada Catalina Recio Aragonés, que se había casado con un médico del Santo Oficio llamado Juan Rodríguez Vicente ${ }^{18}$. Estas genealogías eran las de Fernando Aragonés, rebisabuelo de Juan Recio, realizada en torno a 1500; Elvira Alonso, labrandera, hermana del anterior, realizada en 1521; Gonzalo Aragonés, hermano también de los anteriores, realizada en Palma del Río en 1519; Alonso Aragonés, hijo del anterior, realizada en Palma del Río en 1567; Francisco Pérez, escribano público de Córdoba, realizada en Córdoba en 1562 .

Reconstruyamos, basándonos en esos datos, la auténtica historia familiar. El aljabibe Fernando Aragonés (rebisabuelo de Juan Recio) se había reconciliado en tiempo de Gracia y había desfilado ante el santo Oficio para lograr su habilitación en 1497, por la que pagó 800 ducados $^{19}$. Años después, como otros muchos conversos, declaraba su genealogía ante el Santo Oficio de Córdoba ${ }^{20}$. Casado con una tal Leonor Alonso, había tenido cuatro hijos llamados Beatriz, Alonso, Gonzalo e Isabel, difunta.

Declaraba Fernando, siguiendo el trámite habitual, sus padres y los de su mujer. Él era hijo del labrador Alonso Rodríguez Aragonés y de Beatriz González, ya fallecidos. Sus abuelos paternos eran el labrador Fernando Alonso Aragonés y Elvira Alonso, mientras los maternos eran el trapero Gonzalo Ruiz y Leonor González, todos conversos, pero ninguno reconciliado, simple y llanamente por haber fallecido antes del establecimiento de la Inquisición cordobesa.

Su mujer, Leonor Alonso, era también conversa por los cuatro costados. Sus padres eran Gonzalo Alonso de Montoro y Leonor González. Él había sido reconciliado de la gracia, por lo que fue uno más de los miles de conversos cordobeses que se acogieron a la composición de $1497^{21}$ :

"Gonzalo de Montoro, curtidor, e Leonor González, su mujer, vecinos de san Nicolás de la Ajerquía, 2.600 maravedís".

En su declaración Fernando Aragonés afirmaba que los abuelos paternos y maternos de su mujer tampoco se habían reconciliado. Eran Fernando Alonso de Montoro y Leonor Alonso, de parte de padre, y Alonso Ruiz de la Fuente y Juana González, de parte de

18 José Antonio Martínez Bara, Catálogo de informaciones genealógicas..., t. 2, p. 686. El expediente está desaparecido.

19 AGS, CMC, leg. 100. S.f. Asiento 553.

20 Su declaración la hallamos en el expediente de Limpieza de Juan Recio (AHN, Inquisición, leg. 5213expediente 7). Aunque la fecha es indeterminada, debió producirse como mucho a comienzos del siglo XVI, ya que su hermano, Gonzalo Aragonés, en 1519 señaló que era el mayor de todos y que había fallecido hacía 23 o 24 años. Sabemos que no podía hacer tanto porque se habilitó en 1497, por lo que debió fallecer poco tiempo después.

21 AGS, CMC, leg. 100, s.f. Asiento. 425. 
madre. No obstante, encontramos una referencia en la composición de 1497 en la que aparece un Alonso Ruiz de la Fuente, sastre, habilitándose. Sin embargo, no coincide el nombre de su mujer con el declarado por Fernando Aragonés ${ }^{22}$ :

"Alonso Ruiz de la Fuente, sastre, e Leonor Sánchez, su mujer, vecinos de san Nicolás de la Ajerquía, e Aldonza Ruiz, su hija, son todos reconciliados, 1.500 maravedís".

Quizá esta Leonor Sánchez fuera su segunda mujer o una simple coincidencia, aunque resultaría más lógico lo primero. Por más que buceáramos en los archivos locales y tratáramos de conectar familiarmente a este Fernando Aragonés con el regidor lucentino, la escasez de datos lo haría imposible. Nos ha ocurrido con muchas familias, cuya historia, tras la habilitación y una posible declaración posterior, nos es imposible reconstruir en tanto habría que conocer absolutamente toda la documentación archivística cordobesa y, aun así, sería harto complicado, pues mudaron apellidos, se movieron geográficamente $y$, en general, se desligaron de su pasado más comprometedor. En este caso, sin embargo, tenemos la fortuna de contar con más declaraciones que nos permiten realizar conexiones familiares que abarcan más de ciento cincuenta años.

Pocos años después, en 1521 declaraba su genealogía ante el Santo Oficio Elvira Alonso, labrandera, viuda del ropero Hernando de Montoro, hermana del antedicho Fernando Aragonés. Decía ser natural y vecina de Córdoba ${ }^{23}$. Sabemos que ambos eran reconciliados, por su propia declaración y porque se acogieron a la composición de $1497^{24}$ :

"Hernando de Montoro, aljabibe, e Elvira Alonso, su mujer, vecinos de san Pedro, son reconciliados, 2.500 maravedís".

Elvira Alonso era hermana de Fernando Aragonés, rebisabuelo de Juan Recio. Declaraba en 1521 cuando contaba con 65 años de edad y ampliaba la información que había dado su hermano. Afirmaba que Alonso Rodríguez Aragonés era su padre, difunto en 1465, y había sido labrador y vecino del Alcázar Viejo. Su madre era, según ella, Beatriz Fernández -y no González- difunta un año antes, en 1464. Ninguno, lógicamente, había sido reconciliado. Sus abuelos paternos habrían muerto hacía más de 50 años. Recordemos, eran el labrador Fernando Alonso Aragonés y Elvira Alonso.

22 Ibidem, Asiento. 375.

23 AHN, Inquisición, leg. 5213, exp. 7 y AHN, Inquisición, leg. 1492, exp. 1. En este último hemos hallado la genealogía de su nieta, Catalina Fernández, mujer del trapero Juan de Córdoba (fols. 97-97v). Curiosamente, no hemos encontrado su genealogía en este expediente, aunque se alude a ella en varias ocasiones. 24 AGS, CMC, leg. 100, s.f. Asiento 554. 
Más amplió esta información Gonzalo Aragonés, hermano de los anteriores, cuya declaración, realizada en 1519, está contenida en el libro de genealogías de Palma del $\mathrm{Rí}^{25}$. Tenía 62 años y por tanto era algo menor que su hermana. Él declaraba ser natural de Zaragoza, lo que confirmaría la oriundez de los Aragonés, pero se había criado en Córdoba, porque allí vivió su padre. Había tenido un primer matrimonio con Catalina Gutiérrez de Andújar, de la que tan sólo sabemos que fue reconciliada. Su segundo matrimonio se había producido con Mencía Fernández, también reconciliada. Debió casar antes de 1497, ya que junto a ella acudió ante el Santo Oficio a habilitarse, tal y como habían hecho muchos de sus parientes ${ }^{26}$ :

"Gonzalo Aragonés, corredor, e Mencía Fernández, su mujer, vecinos de santa María, son reconciliados y ella es hija de condenado, 1.200 maravedís".

Sus hermanos eran los citados Elvira Alonso y Fernando Aragonés -según el declarante muerto hacía 23 o 24 años- que era el mayor de todos, y una tal Leonor Rodríguez, viuda en 1519 de Gonzalo de Luque, aljabibe. Estos últimos también se habían habilitado en 1497, siendo vecinos de Santo Domingo, tras pagar la suma de 2.000 maravedís $^{27}$.

Hasta aquí, básicamente nos encontramos a una de tantas familias conversas cuyos miembros tras convertirse hubieron de reconciliarse y, años después, habilitarse. Ocupaban oficios típicos de cristianos nuevos, como aljabibe, labrandera, corredor, etc. y por las cuantías que pagaron por su habilitación no mostraban una gran capacidad económica, aunque es cierto que las cantidades estaban por encima de la media. Todos ellos representaban, ni más ni menos, que el tronco original de una familia que siglos después obtendría el marquesado de Campo de Aras (1806). Por línea de varonía Fernando Alonso Aragonés, fallecido en torno a 1450, suponemos que judío de nacimiento y primer converso del linaje, tuvo por hijo a Alonso Rodríguez Aragonés, labrador, y éste supuestamente llegado a Córdoba desde Zaragoza fue padre de Fernando Aragonés, aljabibe reconciliado, rebisabuelo de Juan Recio Aragonés, regidor de Lucena, familiar del Santo Oficio, Alguacil Mayor de la Villa ${ }^{28}$.

\footnotetext{
25 Igual que ocurre en el caso de su hermana, entre las genealogías que tenemos de Palma del Río no habíamos hallado ésta, que sí se encuentra en el expediente de limpieza de Juan Recio (AHN, Inquisición, leg. 5213, exp. 7).

26 AGS, CMC, leg. 100, s.f., Asiento. 143.

27 AGS, CMC, leg. 100, s.f. Asiento. 733.

28 Lo de Alguacil Mayor en Ángel Ma Ruiz GÁLVEz, "Guardar las apariencias: formas de representación de los poderes locales en el medio rural cordobés en la época moderna", Historia y Genealogía, 1 (2011), pp. 167-187.
} 
Veamos, hasta aquí, cuál era la genealogía familiar:

\section{Familia Aragonés. (1450-1520)}

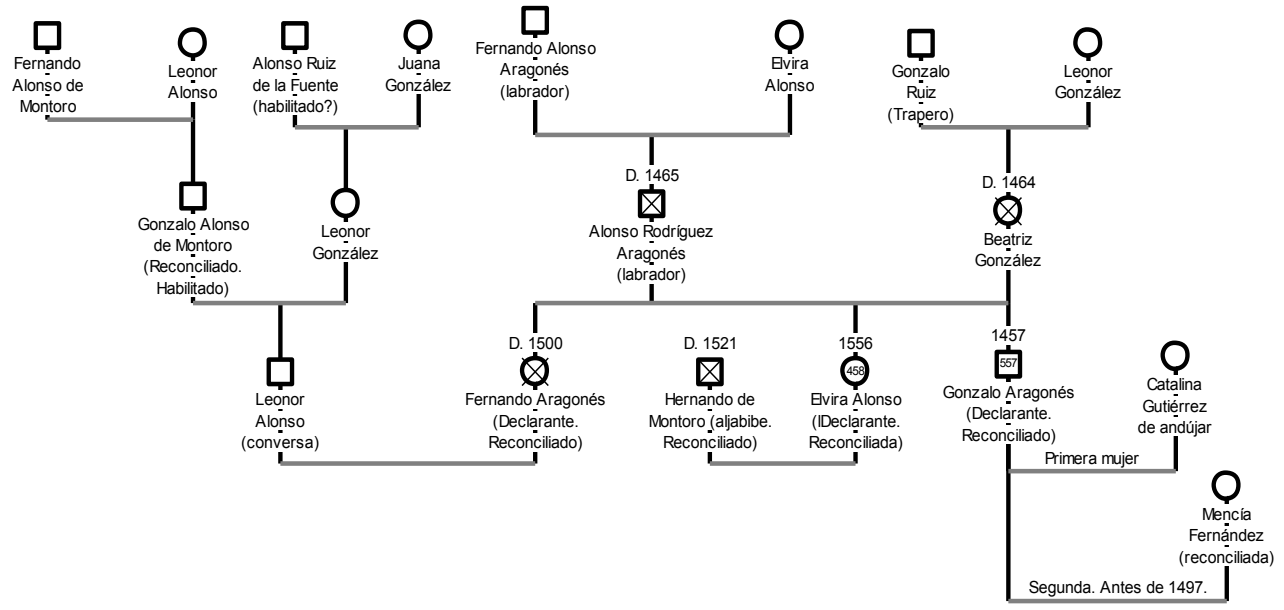

¿Cómo podemos enlazar a estos Aragonés, ya ancianos en torno a 1520, con el regidor lucentino Juan Recio Aragonés? La clave nos la dan genealogías declaradas más de cuarenta años después, la del escribano público de Córdoba Francisco Pérez (1562) y la del corredor Alonso Aragonés, vecino de Palma del Río, de 80 años, ambas también contenidas en el expediente sobre la familiatura de Juan Recio, aunque la primera también la hallamos en otros documentos inquisitoriales.

Tomamos como referencia, y aquí está la clave, la declaración que realizó el escribano público Francisco Pérez ante el Santo Oficio en Agosto de $1562^{29}$. El escribano acudió ante el notario inquisitorial cuando contaba con 26 años para declarar su familia paterna y materna.

Era hijo del procurador Luis Hernández y de Juana Gutiérrez, ambos naturales y vecinos de Córdoba, ambos de generación de confesos. No sólo era converso, sino también descendiente de penitenciados por el Santo Oficio. Por su línea paterna descendía del procurador Hernando de Córdoba, que estuvo preso en el Santo Oficio cordobés y salió con hábito por un año. Por esta rama familiar, Francisco Pérez era pariente de otro importantísimo linaje converso: Los falsos Fernández de Córdoba, que llegarían a marqueses de Canillejas, descendientes del también escribano público Gonzalo Fer-

29 AHN, Inquisición, leg. 1492-1, fols. 41v-44. 
nández de Córdoba ${ }^{30}$. Este último era hijo del procurador Diego Hernández, tío paterno de Francisco Pérez. Por tanto, descendía por su costado paterno de un linaje aparentemente humilde, tocado por la Inquisición. Un linaje que, sin embargo, no encontró impedimentos por su origen judaizante, y que en una de sus ramas protagonizó uno de los ascensos sociales más vertiginosos, desde el escribano Gonzalo Fernández -de Córdoba- a la grandeza de España a fines del Antiguo Régimen.

La línea paterna del escribano es de sobra conocida por los trabajos citados y por lo que hemos ido comentando en páginas precedentes. Recojamos, a modo de resumen, el árbol de este costado familiar.

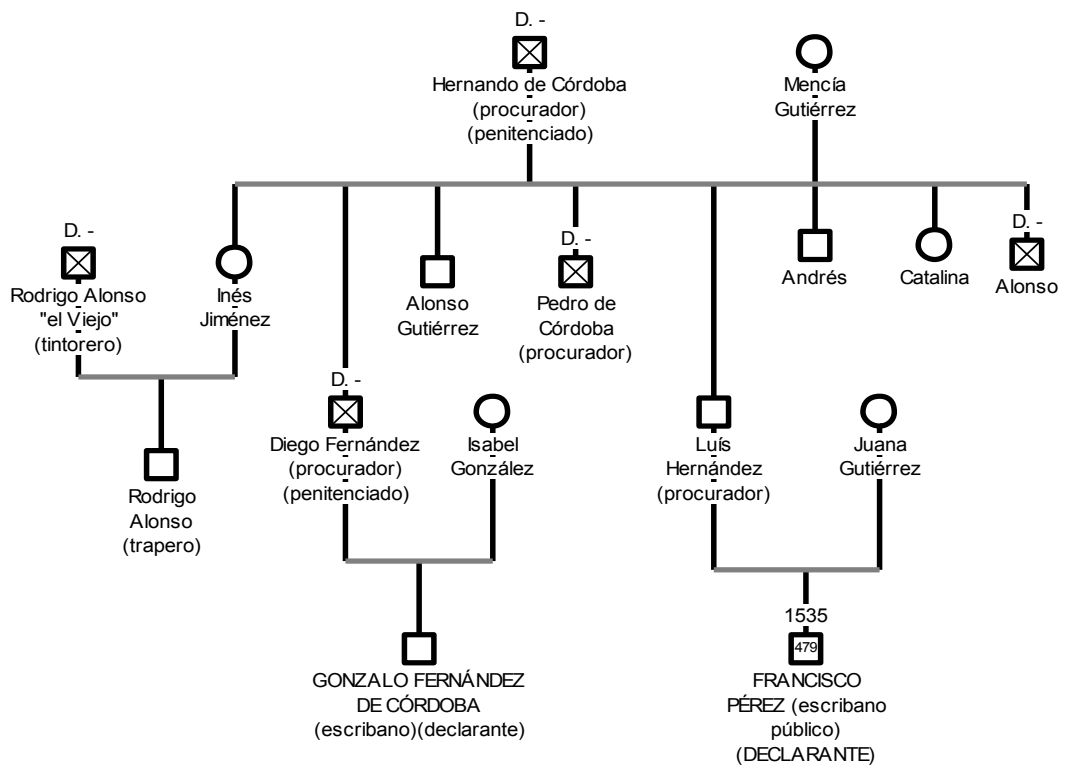

Pero, como se ha dicho, resulta de mayor interés ahora detenernos en una parte de la declaración de Francisco Pérez. Por su línea materna nada fuera de lo normal. Descendía de un sedero natural de Córdoba llamado Juan Sánchez y de una tal Juana Ruiz, natural de Montilla (Córdoba), pero que se había criado en la ciudad de Córdoba. Tenía tan sólo un tío materno llamado Fernán Sánchez, que había emprendido la aventura americana, pues había pasado a Indias en una fecha indeterminada. Su madre tenía dos hermanastros, hijos bastardos de su padre: Juan Sánchez, platero en Córdoba y vecino de la collación de Santa María, donde tenía tienda de platería; y el sastre Andrés Sánchez, del que tenía menos noticias. Hasta aquí todo es normal. La sorpresa aparece cuando

30 AHN, Inquisición, leg. 1423, fols. 7-8v. El profesor Enrique Soria estudió esta familia en El cambio Inmóvil, pp. 161-166. Gonzalo Fernández de Córdoba declaró su genealogía en Agosto de 1562. 
Francisco Pérez declara que había oído que su abuela materna, Juana Ruiz, antes de casarse con su abuelo había tenido un primer matrimonio con Alonso Aragonés, con el que tuvo un hijo llamado Fernando Aragonés que era platero vecino de Córdoba y que por entonces todavía vivía. Este Fernando era, ni más ni menos, que el abuelo del protagonista de esta historia, Juan Recio Aragonés.

Nada más informó el escribano sobre este hermanastro de su madre y tras mostrar la composición y el breve del papa, que lo habilitaba para el ejercicio de su oficio, los inquisidores lo dejaron marchar. Sin embargo, pocos días después, a comienzos de septiembre, Francisco Pérez añadió nuevos datos a su genealogía "porque se le dijo que se informase de los demás de su genealogía y lo había hecho"31. De los datos que aportó en su segunda visita al tribunal inquisitorial, lo más relevante es que se había informado sobre los hijos del hermanastro de su madre, el platero Fernando Aragonés. Estos eran:

\begin{abstract}
"Alonso Aragonés, platero, casado no sabe con quién en Sevilla y vive en Córdoba. Gregorio Aragonés, notario de la audiencia del provisor; y que tiene otros que no conoce, los dos son plateros y viven en Lucena y los otros están con su padre, lo cual dijo ser verdad so cargo de su juramento, ante mí el dicho Juan Castellón, notario"'32.
\end{abstract}

Resulta que dos hermanastros de su madre, que no conocía el escribano, habían marchado a Lucena, aunque no sabía sus nombres. Córdoba no era un reino inabarcable, sino que más bien sus distintas villas y ciudades estaban estrechamente conectadas, a lo que se suma la inmensa movilidad de los conversos. La declaración de Francisco Pérez es clave, en tanto confirma lo denunciado por el memorial anónimo, que unos hermanos "Aragonés" hijos de un platero llamado Fernando Aragonés se instalaron en Lucena, siendo uno de ellos el padre del regidor lucentino.

Aun así, Francisco Pérez era impreciso, no daba nombres, aunque las coincidencias eran reveladoras. No habríamos dudado en afirmar que eran los mismos, pero para mayor exactitud, esta información algo parca dada por el escribano público en 1562, fue completada unos años después por un anciano vecino de Palma del Río llamado Alonso Aragonés, que declaró su genealogía ante el Santo Oficio en 1567. Tenía 80 años entonces, por lo que había nacido en torno 1487 y declaraba ser hijo del sayalero y corredor Gonzalo Aragonés y de Mencía Fernández, naturales y vecinos de Córdoba ${ }^{33}$. Declaraba entonces el anciano que sus tíos paternos eran Fernando Aragonés, vecino de la calle de la Feria, Elvira Alonso, labrandera, mujer de Hernando de Montoro, trapero, que hacía caperuzas, y Leonor Fernández, mujer de Gonzalo de Luque, ropavejero, todos vecinos de Córdoba.

\footnotetext{
AHN, Inquisición, leg. 1492-1, fol. 43.

Ibídem, fol. $43 \mathrm{v}$.

3 Véase Árbol 1.
} 
Lo más interesante de su declaración viene cuando afirma que su tío paterno, Fernando Aragonés, recordemos, difunto a comienzos del Quinientos, había tenido un hijo sedero llamado Alonso Aragonés, vecino de Córdoba, que casado con "una mujer de Montilla" (Juana Ruiz, abuela materna del escribano Francisco Pérez) habría tenido un hijo llamado Fernando Aragonés (abuelo de Juan Recio). Este Fernando Aragonés había casado con una hija de fulano de Palma, que hacía anteojos, y habían sido padres de fulano, notario de la audiencia episcopal. Sumadas ambas declaraciones a las anteriores, así quedaba la genealogía de los Aragonés:

\section{Familia Aragonés (1450-1567)}

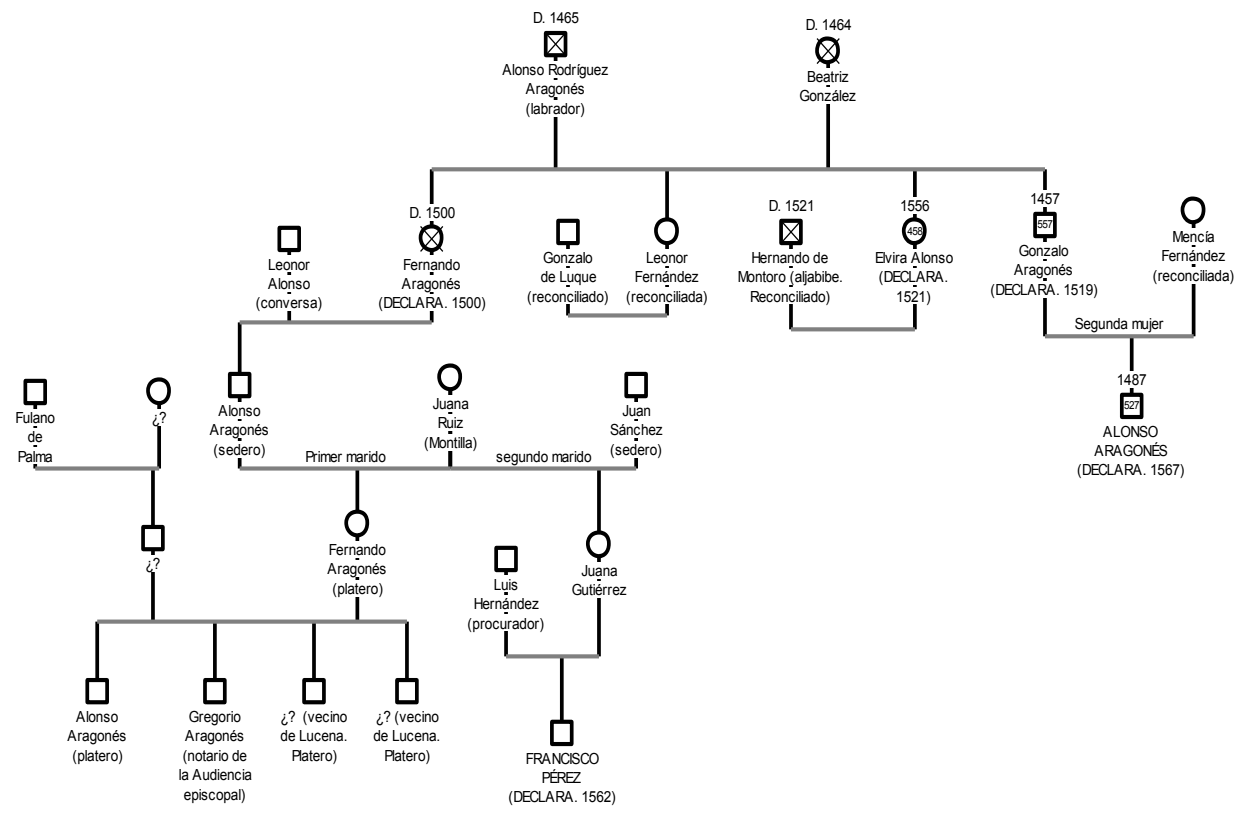

\section{Antepasados directos del Regidor Juan Recio Aragonés}

Todo lo recogido hasta aquí cuadra milimétricamente con las acusaciones vertidas contra el regidor en su probanza, simple y llanamente porque eran ciertas. Basándonos en las declaraciones de genealogías, los memoriales anónimos y sumando documentos hallados en los protocolos notariales, reconstruyamos finalmente quiénes fueron los padres y abuelos del regidor lucentino.

Fernando Aragonés, rebisabuelo de Juan Recio, fruto de su matrimonio con Leonor Alonso tuvo un hijo llamado Alonso Aragonés, de oficio sedero. Éste casó en Córdoba con Juana Ruiz, abuela materna del escribano público Francisco Pérez. Tuvieron un solo hijo 
llamado Fernando Aragonés, platero en Córdoba y que todavía vivía cuando su sobrino Francisco Pérez declara ante el Santo Oficio (1562). Fernando Aragonés habría tenido de su mujer Catalina González, hasta donde sabemos, cinco hijos. Dos de ellos, Alonso y Gregorio, habrían permanecido en Córdoba, mientras que otros dos -según la declaración de Francisco Pérez-o tres -según el memorial anónimo- habrían marchado a Lucena en torno a 1555. Los tres eran plateros: Gonzalo, Ciscos y Pedro Aragonés. En un segundo memorial se afinaba todavía más la información. Se decía que Gonzalo Aragonés había matado a un hombre en Córdoba, y por eso se había marchado a Lucena. Aunque era platero de oficio, en Lucena trató en vino "en que ganó muchos ducados" 34 . Se afirmaba que tuvo un hermano en Córdoba que era notario de la audiencia episcopal, que se había ido a Sevilla con el obispo Cristóbal de Rojas en 1571, cuando le hicieron arzobispo. El otro hermano en Córdoba era platero, pobre y vendía anteojos. Esta información cierra el círculo, confirma definitivamente la ascendencia hebrea. Eran Alonso y Gregorio Aragonés, tal y como declaró el escribano Francisco Pérez. Veamos en el siguiente cuadro la naturaleza y condena de los antepasados de Juan Recio:

\begin{tabular}{|c|c|}
\hline \multicolumn{2}{|c|}{ Antepasados de Juan Recio Aragonés y su relación con el Santo Oficio de Córdoba } \\
\hline Nombre & Naturaleza \\
\hline Fernando Aragonés & Reconciliado y habilitado. Da su genealogía en torno a 1500 \\
\hline Elvira Alonso & Reconciliada y habilitada. Da su genealogía en 1521 \\
\hline Hernando de Montoro & Reconciliado y habilitado \\
\hline Gonzalo Aragonés & Reconciliado y habilitado. Da su genealogía en 1519 \\
\hline Mencía Fernández & Reconciliada y habilitada \\
\hline Leonor Fernández & Reconciliada y habilitada \\
\hline Gonzalo de Luque & Reconciliado y habilitado \\
\hline Francisco Pérez & Da su genealogía ante el Santo Oficio en 1562 \\
\hline Alonso Aragonés & Da su genealogía ante el Santo Oficio en 1567 \\
\hline
\end{tabular}

Fuente: AGS, CMC, leg. 100; AHN, Inquisición, leg. 5213, exp.7; AHN, Inquisición, leg. 1492-1. Elaboración propia.

Recapitulemos. Juan Recio Aragonés descendía por su línea paterna indiscutiblemente de conversos e incluso de judaizantes, lo que habría imposibilitado que fuera regidor, familiar del Santo Oficio o que su descendencia obtuviera cargos y honores sólo reservados a cristianos lindos. Su bisabuelo, Alonso Aragonés, había casado con una conversa natural de Montilla, Juana Ruiz, con la que había tenido a su abuelo Fernando Aragonés,

34 AHN, Inquisición, leg. 5213, exp. 7. 
platero en Córdoba. Éste había casado con Catalina González con la que tuvo a Gonzalo, Ciscos, Pedro, Gregorio y Alonso Aragonés, todos conversos, todos a priori inhábiles.

\section{Familia Aragonés (de 1450 a 1612)}

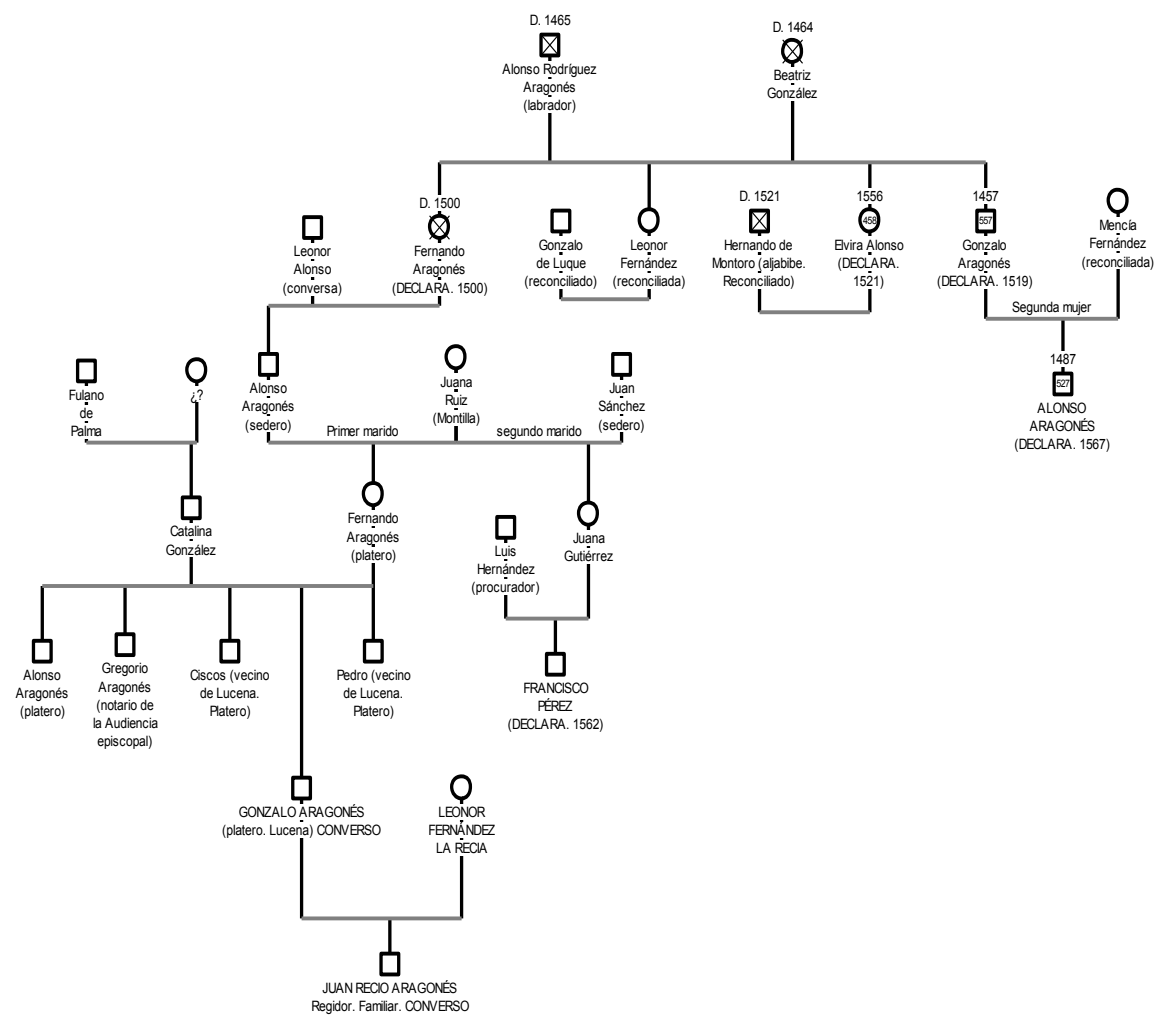

Si tan conocida era la ascendencia conversa en Córdoba, ¿cómo pudieron los Aragonés lucentinos ocultar su progenie y ascender socialmente? Un primer paso fue la "huida" del lugar de origen, una estrategia fundamental. Así, el platero Gonzalo Aragonés, a mediados del siglo XVI se habría afincado en la populosa villa de Lucena. Desconocemos si para huir tras haber asesinado a un hombre, pero lo cierto es que se estableció allí por aquellas fechas, donde dio los primeros pasos para el ascenso familiar. Logró enriquecerse como comerciante y productor de vino ${ }^{35}$. Su poder económico le permitió tener un matrimonio beneficioso con doña Leonor Fernández Recio, de una prestigiosa familia de labradores de la localidad, hija de Juan Recio y de doña María Fernández Casamentero ${ }^{36}$.

35 En varias escrituras su hijo, Juan Recio, aparece como propietario de viñedos.

36 E. Soria Mesa, Las élites judeoconversas en la Andalucia de los siglos XVI y XVII..., p. 6, en prensa. 
Hasta aquí, esta rama de los Aragonés sí había logrado escapar de su pasado converso y enriquecerse, pero el siguiente paso en el ascenso social lo daría su hijo, Juan Recio Aragonés.

En primer lugar, habría que destacar que Juan antepuso el Recio al Aragonés, posiblemente para desligarse de un apellido tan notado en el reino de Córdoba. Seguramente por el patrimonio heredado y por sus propios negocios relacionados con el sector primario, Juan Recio fue uno de los personajes más ricos de la Villa de Lucena. Su fortuna le permitió, en primer lugar, casar con una hidalga vecina de Antequera llamada Inés Chacón de Rojas, hija de Juan Chacón de Rojas y Leonor Hurtado del Valle, y precisamente sería el apellido Chacón, desde entonces, la seña de identidad de la Familia. Fuera cierto o no, los hijos y descendientes de Juan Recio e Inés Chacón, alegarían en el futuro proceder de los Chacón de Antequera, de notoria nobleza. El siguiente paso fue el asalto al poder político y así, el descendiente de conversos logró ser regidor de Lucena y, hacia 1610, Alguacil Mayor de la Villa ${ }^{37}$. Su ascenso social era indiscutible, había logrado acceder al cabildo de una de las principales villas del reino de Córdoba, había casado bien y su pasado hebreo parecía estar totalmente oscurecido.

El ennoblecimiento familiar lo demuestran anécdotas como la recogida por el profesor Ruiz Gálvez. Las familias principales se disputaban los mejores asientos en la parroquia, pues la misa era el principal acto social donde hacer gala de su nobleza. En 1612, en la parroquia de San Mateo de Lucena hubo una encarnizada disputa entre doña Inés Chacón de Rojas, esposa de Juan Recio, con varias hijas de Antón Hurtado por ocupar un determinado asiento, "llegando a increparse con palabras de injuria de una a otras en el interior del templo" "38. Otra muestra de su ascenso social sería la fundación de un mayorazgo por parte Inés ${ }^{39}$.

Esta anécdota demuestra el orgullo de la familia, consciente de ser una de las más poderosas de la Villa. Hacia 1612, cuando decidió presentar su candidatura a familiar, Juan Recio creía tener todo bien atado. Aun así, la invención genealógica le podría servir en caso de que alguien se atreviera a sacar a relucir su progenie, como así fue. La estrategia usurpatoria, en este caso, fue hacerse descender de los Aragonés de Fernán Núñez, descendientes de Alonso Aragonés, escudero de Diego de Sousa. Además, a su servicio tenía mecanismos como la tacha de testigos o la falsedad documental. Veámoslo.

\footnotetext{
37 Aunque no aparece como tal en su candidatura a Familiar del Santo Oficio, sí aparece ostentando este cargo en una escritura de 1610: Archivo Histórico de Protocolos de Córdoba (en adelante AHPCo), Lucena, leg. 2536, fol. 23. Asimismo, esto lo confirma una referencia tomada de Ángel Ma . Ruiz Gálvez, "Guardar las apariencias: formas de representación de los poderes locales en el medio rural cordobés en la época moderna....", p. 186.

38 Recogido por A. Mª Ruiz Gálvez, "Guardar las apariencias: formas de representación de los poderes locales en el medio rural cordobés en la época moderna...", p. 186.

39 Archivo de la Real Chancillería de Granada (en adelante ARChGr), leg. 402-3374-6, año 1717.
} 


\section{Una falsedad probada documentalmente}

Cuando en 1613 aparecieron informaciones que delataban su condición de converso, Juan Recio presentó un memorial para defenderse. Hizo especial hincapié en que había ganado la familiatura contra la candidatura de don Pedro Rico, hijo del difunto, que también la pretendía, que era un "hombre emparentado con la gente más rica y poderosa de la dicha villa". En su recusación de testigos tachaba a casi cincuenta posibles declarantes ${ }^{40}$, la mayoría vecinos de Lucena, algunos tan importantes como el regidor perpetuo Pedro de Rueda Rico, alegando que tanto él como sus deudos lo odiaban, porque Juan Recio había concertado casar a su hija doña Leonor con don Juan de Rueda Rico, su hijo, y anuló el enlace para casarla con don Enrique de Guzmán y Cárdenas, caballero muy principal. Los deudos, amigos y paniaguados del regidor perpetuo lo odiaban, y de ahí que los recuse como posibles testigos. También tacha a otros muchos por rivalidades económicas, por cuestiones de ganado, negocio del que Juan Recio obtenía pingües beneficios ${ }^{41}$.

El pretendiente, entre la espada y la pared, trató de demostrar su genealogía falsa. Su abuelo, Fernando Aragonés, no era un converso cordobés, sino el licenciado Fernando Aragonés, vecino de Fernán Núñez, hijo de un tal Alonso López Aragonés y hermano de Francisco Fernández Aragonés. Éste, vecino también de Fernán Núñez, había casado con Mayor Díaz (de Cañete) hija de Alonso Ruiz Burbano y de Isabel Díaz, el 26 de Junio de 1500. Presenta entonces Juan Recio original en pergamino y traslado en papel de la carta dotal y acrecentamiento de dote otorgada por Francisco Fernández Aragonés (1500 y 1502), por la que habría recibido 57.453 maravedís de dote acrecentada dos años después con 5.745 maravedís. Uno de sus hijos, de los que Juan Recio decía ser pariente, fue Francisco Aragonés, padre de Martín Fernández Aragonés, comisario del Santo Oficio y de Pedro de Heredia Aragonés ${ }^{42}$, familiar del Santo Oficio.

\footnotetext{
40 En el memorial se afirma que Lucena es una Villa de 4.032 vecinos, según consta de cuatro padrones de confesión.

${ }^{41}$ Sus negocios estuvieron relacionados con la ganadería y la agricultura. Por poner algún ejemplo, en 1609 hereda una aranzada de viña y olivar, como pago de un censo que tenía impuesto sobre los bienes de Francisco García Carrillo (AHPCo, Lucena, leg. 2361, fol. 245); en esas mismas fechas, por ejemplo, un vecino de Guadix le paga ciertos maravedís por la venta de aceite que el regidor le había hecho (AHPCo, Lucena, leg. 1998, fol. 41v).

42 José Antonio Martínez Bara, Catálogo de informaciones genealógicas..., t. 2, p. 376. Obtiene la familiatura en 1592-93 sin que haya ninguna traba, En 1613 también llegó a ser Alcalde de la Hermandad del Estado de Hidalgos. Su suegro, Alonso Gómez de Segovia, era familiar del Santo Oficio en Fernán Núñez. No se ha conservado el expediente de su hermano, el presbítero Martín Fernández Aragonés para ser comisario del Santo Oficio, pero se toma como acto positivo para que se le conceda la familiatura. Nada dicen del supuesto escudero, ni de su rama familiar cordobesa, ni del hecho de tener un pariente regidor en la villa de Lucena.
} 
Esta prueba y la tacha de testigos fueron suficientes para que se descartaran los memoriales y, aunque votado en discordia, se le despachara título de familiar en 1614. Ésta sería su genealogía oficial:

\section{Genealogía Oficial. Presentada por el Regidor en su defensa.}

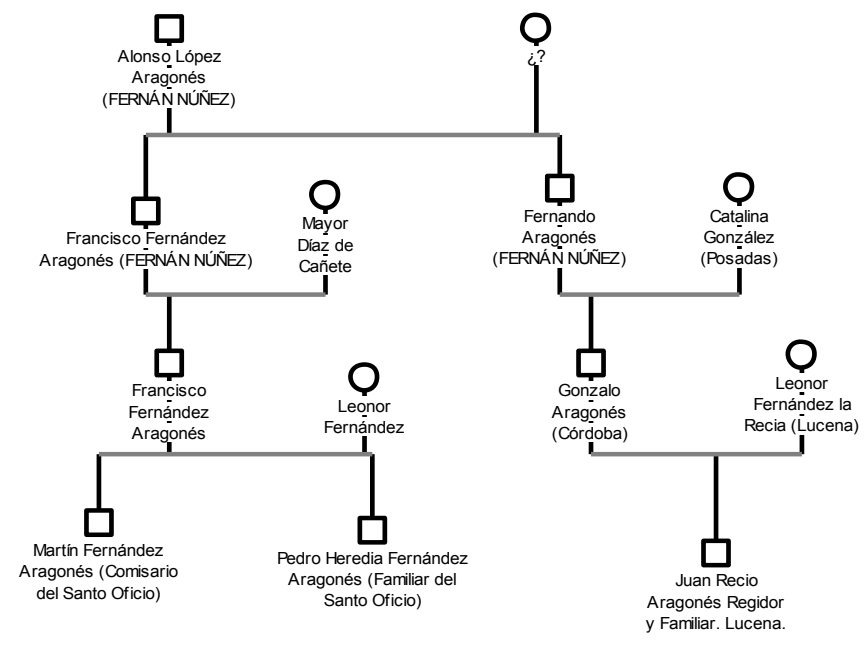

La historia ya estaba hecha. Su familiatura sancionaba legalmente que los Aragonés lucentinos eran limpios de sangre. El dinero, el poder y las influencias políticas, la falsedad documental y, posiblemente, el soborno a los encargados de investigar su auténtica ascendencia, permitieron al regidor demostrar su limpieza y acceder a una familiatura inquisitorial.

Los Aragonés de Lucena despistaron su procedencia geográfica y situaron su origen en la villa de Fernán Núñez, pero la verdad quedó oscurecida a medias, como hemos visto. La estrategia se basó en encontrar una Casa de demostrada limpieza y de idéntico apellido y hacerse descender de ella. No buscaron unos antepasados magníficos, pero sí lo suficientemente limpios como para que las pruebas documentales aportadas al proceso bastaran.

Pero no hemos de dejar en el tintero un aspecto más en su proceso de ocultación. Para poder demostrarlo, llevaron a cabo la falsificación documental. Como señaló el profesor Soria, "Si hacían falta testigos, se les sobornaba, como era práctica corriente entre sus contemporáneos, y si llegaba el caso se falsificaban documentos, pagando a escribanos especializados en tan ilícita tarea"43.

43 Enrique Soria Mesa, Las élites judeoconversas en la Andalucía de los siglos XVI y XVII..., p. 14, en prensa 
Además de la carta dotal de un supuesto tío abuelo -datada en 1500, por lo que cronológicamente no cuadraba-, en los protocolos notariales lucentinos todavía hoy se conservan dos escrituras falsas ${ }^{44}$. Dichos documentos son la prueba irrefutable de una mentira, la mil veces repetida: los Aragonés de Lucena provenían de los Aragonés de Fernán Núñez. El primero es una escritura en la que Fernando Aragonés (abuelo del pretendiente) decía ser vecino de Fernán Núñez y residente (1535) en Lucena. Informa en dicha escritura que cuando Alonso López Aragonés, su padre, llegó a un acuerdo con Alonso González de Aguilera, su suegro, natural de Porcuna, casó en Santa Marina de Córdoba con Catalina González en 1535, recibiendo 400 ducados de dote. Recordemos, si este Fernando Aragonés era hermano de Francisco Fernández Aragonés, ¿Cómo es posible que Francisco casara más de 30 años antes que su hermano? El segundo documento es la dote de su hijo Gonzalo Aragonés, natural de Córdoba y vecino de Lucena, hijo de Fernando Aragonés, natural de Fernán Núñez y de Catalina González Aguilera, natural de Porcuna, para casarse con Leonor Fernández Recio, hija de Juan Recio y doña María Fernández Casamentero, vecinos de Lucena. En ambos documentos se explicita que Fernando Aragonés era natural y vecino de Fernán Núñez, hecho fundamental para desviar su vecindad y naturaleza en la ciudad de Córdoba.

Habían insertado en los protocolos notariales lucentinos dos escrituras completamente inventadas, pero que serían especialmente útiles a la descendencia de estos falsos cristianos viejos ennoblecidos. Además, se emparentaba a Fernando Aragonés, abuelo paterno de Juan Recio, con Catalina González, supuesta hija de Alonso González de Aguilera, de "conocida familia hidalga comarcana" despistando para siempre las posibles dudas que pudieran surgir sobre su naturaleza. Recordemos que según otras declaraciones Fernando Aragonés había casado con Catalina González, sí, pero hija de fulano de Palma, que hacía anteojos ${ }^{45}$.

¿Por qué no fueron presentados ambos documentos por el regidor cuando se puso en tela de juicio su limpieza? Pensamos que simple y llanamente porque la falsificación se hizo después y fue introducida en los protocolos lucentinos por alguno de sus descendientes. Muchos de ellos tuvieron que demostrar limpieza y quizá conocedores de su ascendencia conversa reforzaron su historia con documentos falsos que demostraban lo que decían ser, limpios de sangre, hidalgos y nobles por sus cuatro costados. Sabemos, porque así consta en las escrituras, que en 1765 se dio copia a don Martín y don Gabriel Recio Chacón, hermanos, quintos nietos del señor Fernando Aragonés, y cuartos de Gonzalo, su hijo primogénito ${ }^{46}$. Quizá también le fueron útiles al biznieto

\footnotetext{
44 Dicho hallazgo lo hizo el Dr. Enrique Soria Mesa. En sus investigaciones sobre los conversos cordobeses halló en el AHPCo, Lucena, leg. 2044, años. 1554, 1558, 1560, dos escrituras, tal y como él mismo afirma, de letra distinta a la del protocolo, imitando letra antigua, escrituras que se nota que fueron recosidas posteriormente y de la que se dio copia a dos descendientes de Juan Recio Aragonés en 1765, concretamente al Alguacil Mayor perpetuo honorario de Martos y Familiar del Santo Oficio, don Martín Recio Chacón y Guzmán y a su hermano don Gabriel Recio Chacón y Guzmán.

45 AHN, Inquisición, leg. 5213, exp. 7.

46 AHPCo, Lucena, leg. 2044, años. 1554, 1558, 1560.
} 
de nuestro protagonista, Fernando Recio Chacón de Rojas, vecino de Lucena, cuando solicitó certificado de aprobación de informaciones, presentando para ello documentos probatorios; o al hijo del anterior, el familiar del Santo Oficio Gabriel Recio Chacón Guzmán, que en 1764 también solicitó certificado de aprobación de informaciones.

A fin de cuentas, cuando Juan Recio logró la familiatura, logró el aval definitivo a su proceso de ascenso y ocultación. Legitimó su falsa limpieza, culminó un ennoblecimiento gestado durante años. A partir de aquí su descendencia gozaría de los más altos cargos y honores, aquellos que permitieron a los Aragonés cordobeses pasar de judíos a marqueses. La familiatura de Juan Recio constó como acto positivo para muchos de sus descendientes. Por ejemplo, sirvió a don Martín Recio Chacón y Guzmán, Alguacil Mayor perpetuo honorario de Martos, natural de Lucena, cuando en 1733 quiso ser familiar; a Gabriel Recio Chacón, que fue ministro del Santo Oficio ${ }^{47}$; también a sus hijos Fernando Recio Chacón de Mesa, natural de Lucena, cuando logró una familiatura en 1757 (Juan Recio era su cuarto abuelo); o a su hermano Tomás Recio Chacón y Mesa, presbítero, natural de Lucena, para ser Notario supernumerario en $1793^{48}$.

Como hemos visto en otras historias familiares estudiadas, aunque con diferencias, a rasgos generales las historias se repiten. Y una vez logran ser considerados nobles, apoyándose siempre en su poder económico, su descendencia llegará a las más altas cotas de poder. Veamos de una forma descriptiva, cuáles fueron los descendientes del regidor converso, Juan Recio Aragonés ${ }^{49}$ :

1. Doña Catalina Recio Aragonés, casada con Juan Rodríguez Vicente, familiar del Santo Oficio de Valencia (no se conserva su expediente).

2. Doña Leonor Recio Chacón, casada con don Enrique de Guzmán y Cárdenas.

3. Gonzalo Recio Aragonés, familiar del Santo Oficio.

4. Francisco Recio Chacón de Rojas. Casó en Lucena con Francisca Carrillo de Córdoba. Tuvieron tres hijas:

4.1. Doña María Josefa Recio Chacón de Rojas y Carrillo, casada con su pariente Juan Félix Chacón de Rojas y Merino Hurtado de Mendoza. Su hijo, don Diego José Chacón de Rojas, vecino de Antequera, pleiteará por la sucesión del mayorazgo fundado por doña Inés Recio Chacón, mujer de Juan Recio Aragonés, desde $1706^{50}$.

\footnotetext{
47 No existe su expediente.

48 Un resumen de sus procesos en José Antonio Martínez BARA, Catálogo de informaciones genealógicas..., t. 2, pp. 686-689.

49 Para hacer la descripción de su descendencia nos hemos apoyado principalmente en el Expediente de solicitud del marquesado de Campo de Aras del I Marqués, sito en el Archivo del Ministerio de Justicia, año 1799 y en los trabajos de Óscar BAREA López, Heráldica y genealogía de los linajes de Cabra de Córdoba,..., t. 2, pp. 234-235 y José Antonio MARTínez BARA, Catálogo de informaciones genealógicas..., t. 2, pp. 686-689.

50 ARChGr, leg. 402-3374-6, año 1717.
} 


\subsection{Francisca Recio Chacón de Rojas y Carrillo.}

4.3. Estefanía Recio Chacón de Rojas y Carrillo.

5. Fernando Recio Chacón de Rojas. Con él continúa la descendencia. Casó con doña María doña María Curado de Velasco, hija de Gabriel Muñoz Curado y Hernández, familiar del Santo Oficio en Lucena y regidor de Lucena, y Ana de Velasco. Los hijos de este matrimonio fueron:

5.1. Gabriel Recio Chacón de Rojas ${ }^{51}$ o Gabriel Recio Chacón Curado de Velasco, Alférez Mayor y regidor de Lucena. Casado en Aguilar con doña María del Valle Becerra. Fueron padres de:

5.1.1. Fernando Recio Chacón de Rojas Valle y Becerra ${ }^{52}$, natural de Lucena, alcaide del Castillo y fortaleza de Chillón. Casó en Morente en 1705 con doña Elvira María de Guzmán el Bueno Méndez de Sotomayor, vecina de Córdoba, y fueron padres de don Martín José Recio Chacón y Guzmán, don Gabriel Recio Chacón y Guzmán, María Francisca, Teresa y Agustina.

A) El primero, Martín José Recio Chacón y Guzmán el Bueno, nacido en Lucena en 1711, Alférez Mayor y regidor de Lucena, Alguacil perpetuo honorario de Martos, probó su limpieza para familiar en $1733^{53}$. Casó en Lucena en 1734 con Catalina Rosalía López Hogazón Curado Fernández de Córdoba, de Lucena. Fueron padres de María Araceli5 ${ }^{54}$, Luis, Francisco y Francisca y:

Martín José Chacón y Hogazón o Chacón Guzmán el Bueno López Hogazón Curado Fernández de Córdoba ${ }^{55}$, nacido en Lucena, Maestre de Campo del Real Cuerpo de Sevilla, Alguacil Mayor perpetuo honorífico de Martos, síndico personero en 1800, que probó su limpieza en 1799 para ser familiar y obtuvo el marquesado de Campo de Aras en 1806, casado con doña Manuela Altamirano y Escobedo Benegas Fernández de Córdoba, vecina de Martos, III marquesa de Alhendín.

\footnotetext{
51 En la Chancillería de Granada hemos localizado un pleito fechado en 1717 entre don Gabriel Recio Chacón de Rojas, vecino y regidor de Lucena, con don Diego José Chacón de Rojas, vecino de Antequera, "sobre la sucesión del vínculo y mayorazgo que fundó doña Inés Recio Chacón, mujer que fue de Juan Recio Aragonés" (ARChGr, leg. 402-3374-6, año 1717).

52 José Antonio Martínez Bara, Catálogo de informaciones genealógicas..., t.2, p. 686.

53 Ibídem, p. 687.

54 Nacida en Lucena en 1758. Casó con un hidalgo lucentino llamado Martín Cortés y fueron padres de Vicente Cortés y Chacón, Ayudante Mayor de Guardias Españolas, hidalgo en Lucena en 1794 y Caballero de Calatrava desde 1814.

55 Así consta en su expediente recogido por José Antonio Martínez Bara, Catálogo de informaciones genealógicas..., t. 2, pp. 687-688.
} 
B) Gabriel Recio Chacón y Guzmán, familiar del Santo Oficio ${ }^{56}$, casado con Rafaela Nicolasa de Mesa Hurtado y Pausa. Padres de Tomás Recio Chacón y Mesa, natural de Lucena, presbítero, que probó su limpieza de sangre en 1793, para ser notario supernumerario del Santo Oficio ${ }^{57}$; Luis (solicita la familiatura), Nicolás (nacido en Lucena en 1759 fue Guardia Marina desde 1779); Fernando Recio Chacón de Mesa, nacido en Lucena, probó su limpieza para ser familiar en $1756-57^{58}$.

\section{Conclusión}

Si la historiografía supera la visión tradicional sobre la nobleza, si se comienza realmente a reconstruir el origen familiar de gran parte de las élites de nuestro país, descubriremos, como en el caso estudiado, que el judaísmo se encuentra en el origen de un porcentaje bastante considerable de la nobleza española.

Es cierto que tras los dramáticos sucesos vividos por los hebreos en la el siglo XV, muchos quedaron desplazados del un poder que habían ido ganando a lo largo de la centuria. Sin embargo, la habilidad inherente a los conversos para dominar sectores económicos especialmente lucrativos, su capacidad de ocultación y, sobre todo, las contradicciones propias de aquel complejo mundo, permitió a los descendientes de condenados por la Inquisición volver a asaltar los municipios, dominar el comercio y la artesanía, convertirse en miembros de la oligarquía local, primero, y de la nobleza titulada, después.

Así, ni un sentir popular radicalmente anticonverso, ni una legislación discriminatoria, pudieron frenar las ambiciones de muchos miembros de la minoría. Por eso, proyectos como en el que se inscribe este trabajo, tratan ni más ni menos de desvelar el origen judío de una parte de la nobleza española.

En definitiva, a medida que nuestro conocimiento sobre aquella sociedad sea más profundo descubriremos que casos como el de los Recio Aragonés, que hoy nos parecen "excepcionales", fueron habituales, que la permeabilidad de los estamentos sociales era enorme, que los judeoconversos no sólo llegaron a titular como nobles, sino que fueron también artesanos, comerciantes, clérigos... o simples pecheros, pues andando el tiempo, lograda su completa asimilación, se convirtieron en fiel reflejo de la sociedad del tiempo en el que les tocó vivir.

\footnotetext{
56 No existe su expediente para familiar del Santo Oficio. José Antonio Martínez Bara, Catálogo de informaciones genealógicas..., t. 2, pp. 686-687.

57 José Antonio Martínez Bara, Catálogo de informaciones genealógicas..., t. 2, p. 688.

58 Ibidem.
} 


\section{DE FERNANDO ARAGONÉS \\ AL PRIMER MARQUÉS DE CAMPO DE ARAS (1550-1806).}

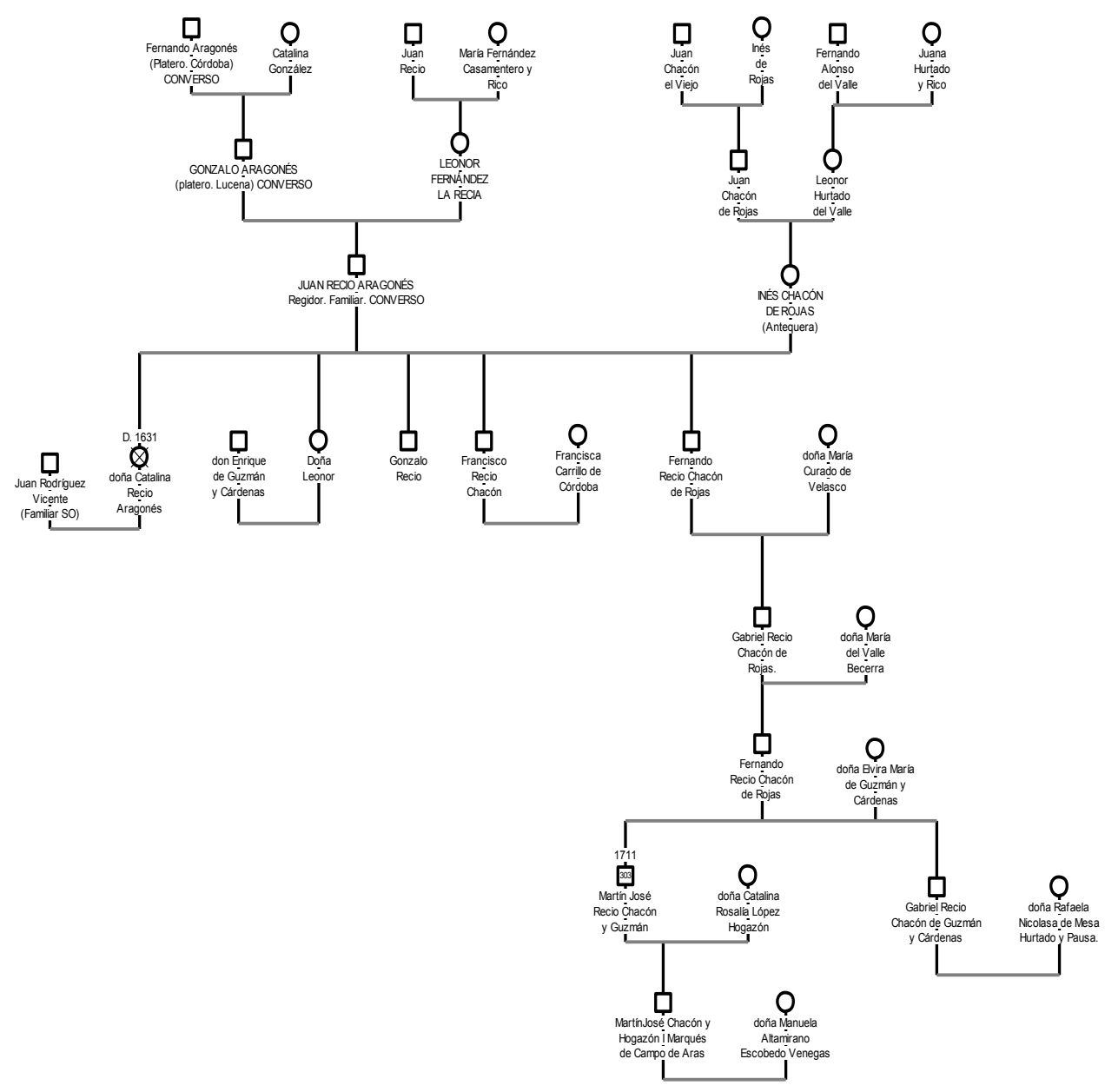

Fecha de recepción: 26 de abril de 2016

Fecha de aceptación: 16 de febrero de 2017 
